\title{
Inflamed retrocalcaneal bursa and Achilles tendonitis in psoriatic arthritis demonstrated by ultrasonography
}

\author{
P V Balint, R D Sturrock
}

Centre for Rheumatic Diseases, University Department of Medicine, Royal Infirmary, 10 Alexandra Parade, Glasgow G31 2ER, UK P V Balint

R D Sturrock

Correspondence to: $\mathrm{Dr}$ Balint

pb58v@clinmed.gla.ac.uk

Accepted for publication 7 June 2000

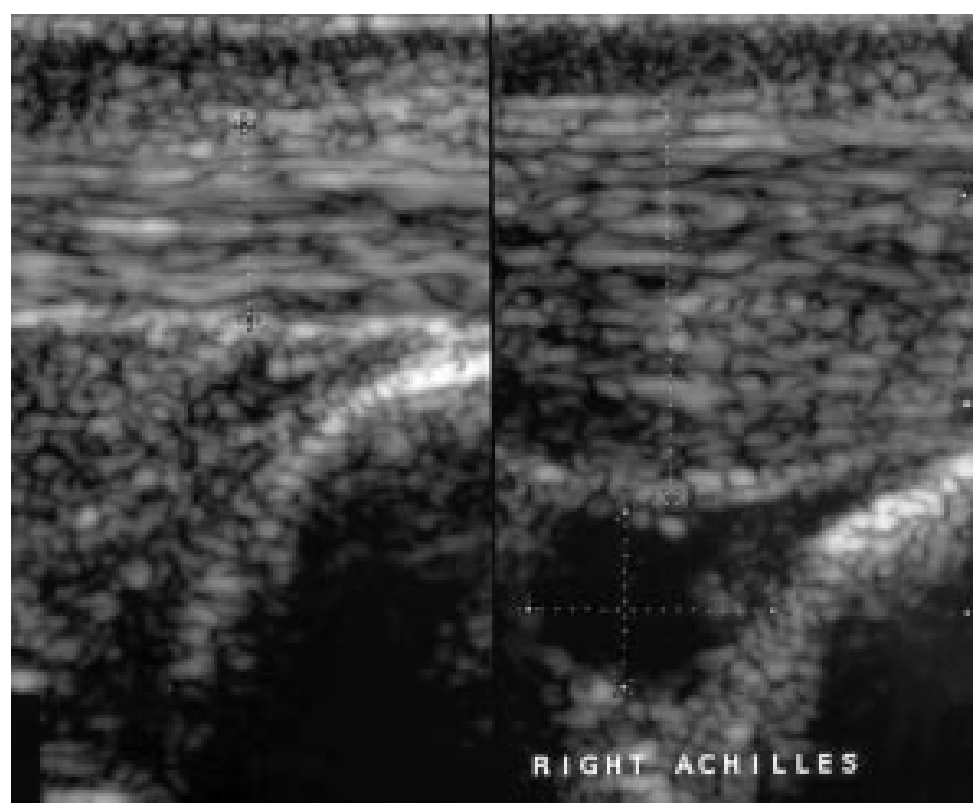

Figure 1 Measurements of the bursa and the Achilles tendon in the sagittal plane on the first occasion. The left Achilles tendon thickness was in the normal range $(0.47 \mathrm{~cm})$. The right Achilles tendon thickness was $0.95 \mathrm{~cm}$. The retrocalcaneal bursa diameters were 0.59 $\mathrm{cm}$ and $0.42 \mathrm{~cm}$.

\begin{abstract}
Objective-To demonstrate the use of high resolution ultrasound measurements and power Doppler mode in the diagnosis and follow up of a patient with psoriatic arthritic with retrocalcaneal bursitis and Achilles tendonitis.

Methods-An outpatient based ATL HDI 3000 ultrasound equipment was used with a CL10-5 MHZ $26 \mathrm{~mm}$ probe and musculoskeletal software. Real time B mode and power Doppler mode were used to detect changes in structure and blood flow.

Results-Unilateral retrocalcaneal bursitis and Achilles tendonitis were demonstrated by sonography. Power Doppler mode was useful to demonstrate an increased blood flow around an abnormal retrocalcaneal bursa. A follow up examination showed marginal thickening of the Achilles tendon without any bursitis.
\end{abstract}

.
heel pain. He was receiving sulfasalazine $2.5 \mathrm{~g}$ and indometacin $75 \mathrm{mg}$ twice daily for his arthritis. Physical examination revealed a swollen and tender right Achilles tendon. In view of his increased disease activity his dose of sulfasalazine was increased from 2.5 to 3.5 g/day.

\section{Methods}

ATL HDI 3000 ultrasound equipment with a CL 10-5 MHZ $26 \mathrm{~mm}$ probe (linear array, small footprint hockey-stick style transducer) was used to image both Achilles tendons without applying pressure. During the examination the patient was in a prone position with his feet freely hanging over the edge of the examination table in a neutral position. After static examination a dynamic examination was performed with the foot in slight dorsal and plantar flexion. The Achilles tendon thickness was measured on both sides. The power Doppler mode was also used with the following parameters: medium flow optimum, low wall filter, dynamic range $55 \mathrm{~dB}$, pulse repetition 

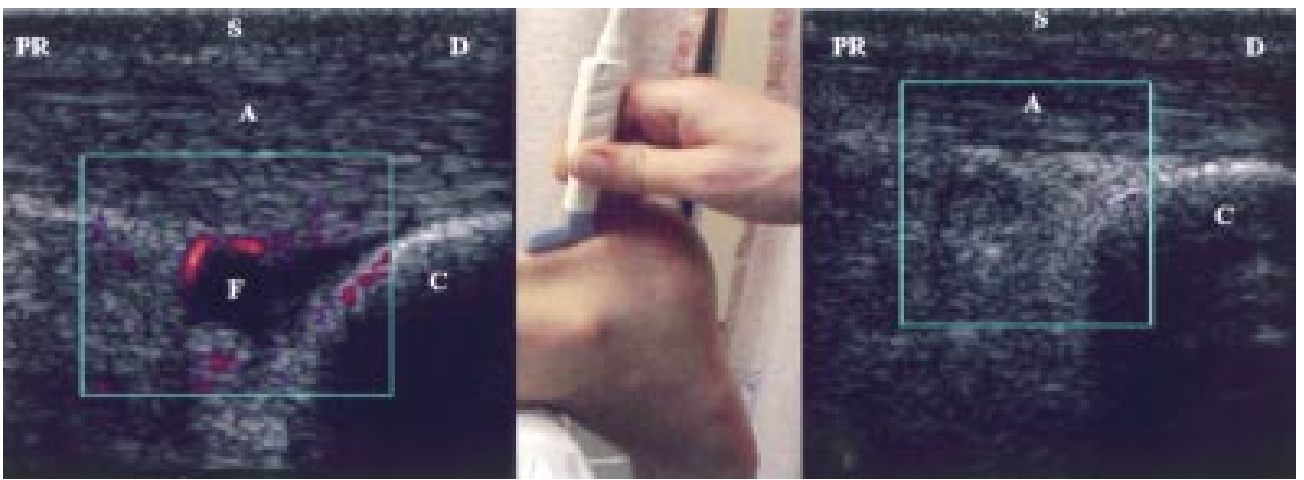

Figure 2 The middle image shows the sagittal scanning position of the distal part of the Achilles tendon. The left image shows the patient's first sagittal sonogram. The right image shows the control sonogram in the same position. PR = proximal; $D=$ distal; $S=$ skin surface; $A=$ Achilles tendon; $C=$ calcaneus; $F=$ fluid in the retrocalcaneal bursa. The green frame signifies the area of a power Doppler scan and the red colour may indicate increased blood flow.
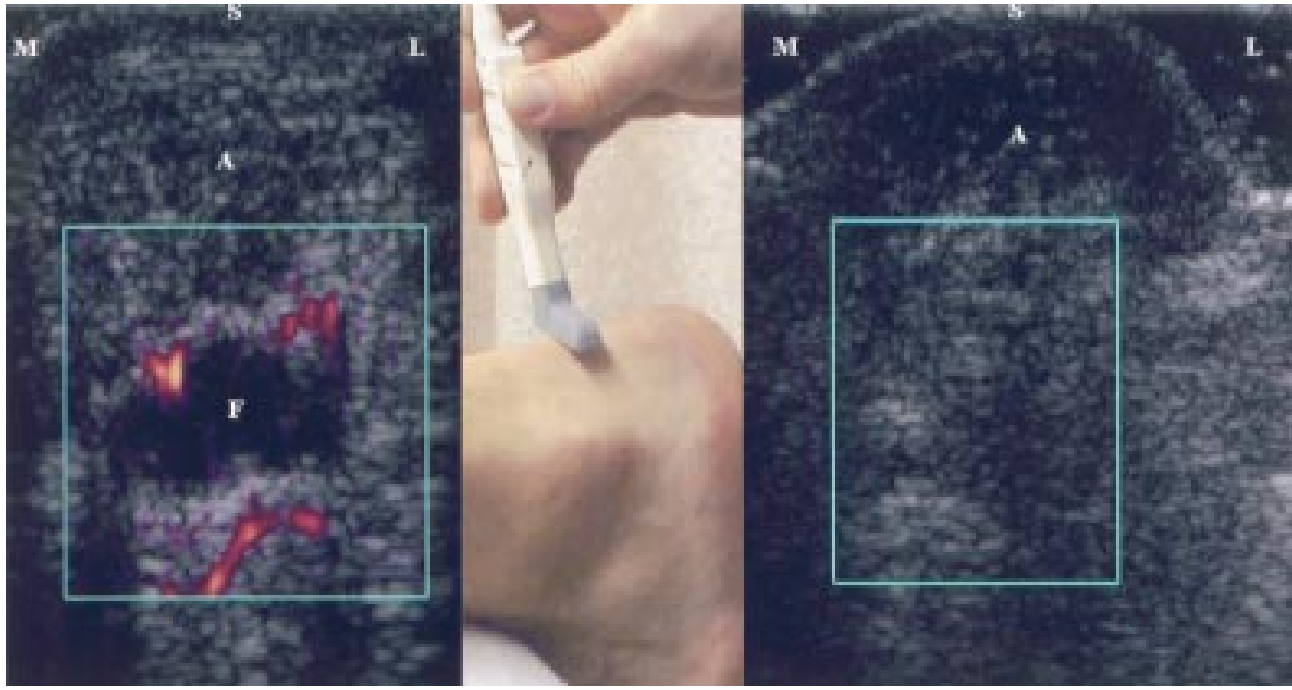

Figure 3 The middle image shows the transverse scanning position of the distal part of the Achilles tendon. The left image shows the patient's first transverse sonogram. The right image shows the control sonogram in the same position. $M=$ medial; $L=$ lateral; $S=$ skin surface; $A=$ Achilles tendon; $F=$ fluid in the retrocalcaneal bursa. The green frame signifies the area of a power Doppler scan and the red colour may indicate increased blood flow.

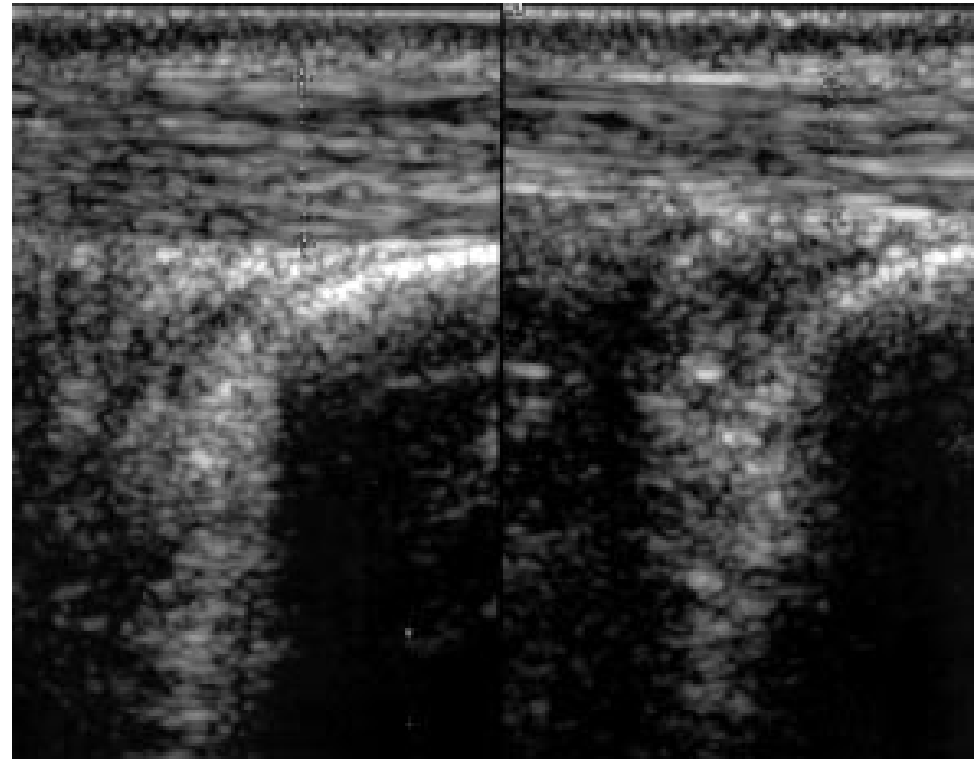

Figure 4 Measurements of the Achilles tendon in the sagittal plane on the second occasion. The left Achilles tendon thickness was again in the normal range $(0.48 \mathrm{~cm})$. The right Achilles tendon thickness (shown on the left hand side of the figure) was $0.60 \mathrm{~cm}$. No fluid could be detected on this occasion. frequency $1000 \mathrm{~Hz}$. After one year a follow up examination was performed. Scans were stored in a magnetic optical disk drive.

\section{Results}

Real time B mode ultrasonography confirmed a thickening of the Achilles tendon and retrocalcaneal fluid accumulation on the right side. Left Achilles tendon thickness was in the normal range $(0.47 \mathrm{~cm})$. The right Achilles tendon thickness was $0.95 \mathrm{~cm}$. The retrocalcaneal bursa diameters were $0.59 \mathrm{~cm}$ and 0.42 $\mathrm{cm}$ (fig 1).

Power Doppler sonography showed increased blood flow around the bursa in the longitudinal and transverse section. One year later when symptoms had clinically resolved, repeat ultrasound examination did not detect a power Doppler signal or fluid collection (figs 2 and 3). The right Achilles tendon was, however, still thicker than the left side $0.60 \mathrm{~cm}$ and $0.48 \mathrm{~cm}$ respectively (fig 4 ). On the normal left Achilles tendon the difference in thickness between the two examinations was only 0.01 $\mathrm{cm}$, which demonstrates a small intraobserver error. 


\section{Discussion}

Clinical examination will easily detect a swollen Achilles tendon in most cases. However, to distinguish between Achilles tendonitis, paratenonitis, and retrocalcaneal bursitis, ultrasonography is required. The Achilles tendon is a relatively large superficial structure, which is easily imaged by ultrasound. Previously, this technique was described without ${ }^{8}$ and with a stand-off $\mathrm{pad}^{9}$ and pitfalls have been recognised. ${ }^{10}$ Normal and abnormal retrocalcaneal bursae have also been studied previously. ${ }^{11-13}$ Ultrasound guided aspiration and corticosteroid injection have been used with excellent results. ${ }^{14}{ }^{15}$ Cunnane and colleagues treated six of 13 patients with retrocalcaneal bursitis with guided corticosteroid injection and all responded well. ${ }^{15}$ This group included two patients who had had a number of unsuccessful non-guided injections. Interestingly, in all 13 cases retrocalcaneal bursitis was associated with postero-superior calcaneal erosions. In our case we could not demonstrate any bony changes, probably owing to the short duration of symptoms.

This case illustrates that ultrasonography can detect pathological changes in Achilles tendonitis and can monitor changes over a long period of time. The use of the power Doppler mode may be helpful in detecting increased blood flow due to inflammation, but standardisation of the technique to ensure reproducibility is difficult. 1 Manger B, Kalden JR. Joint and connective tissue Gltrasonography - A rheumatological bedside procedure?

2 Swen WAA, Bruyn GAW, Dijkmans BAC. Why rheumatologists should be interested in sonography. Rheumatology in Europe 1995;24(suppl 2):98-9.

3 Balint P, Sturrock RD. Musculoskeletal ultrasound imaging: a new diagnostic tool for the rheumatologist? $\mathrm{Br} \mathrm{J}$ Rheumatol 1997;36:1141-2.

4 Leeb BF, Machold KP. Ultrasonography in rheumatology (the sound of arthritis). Rheumatology in Europe 1997;26: 85 .

5 Grassi W, Cervini C. Ultrasonography in rheumatology: an evolving technique. Ann Rheum Dis 1998;57:268-71.

6 Wakefield RJ, Gibbon WW, Emery P. The current status of ultrasonography in rheumatology. Rheumatology 1999;38: 195-8.

7 Grassi W, Lamanna G, Farina A, Cervini C. Synovitis of small joints: sonographic guided diagnostic and therapeutic approach. Ann Rheum Dis 1999;58:595-7.

8 Dillehay GL, Deshler T, Rogers LF, Neiman HL, Hendrix RW. The ultrasonographic characterization of tendons. Invest Radiol 1984;9:338-41.

9 Fornage B. Achilles tendon: US examination. Radiology 1986;159:759-64.

10 Fornage B. The hypoechoic normal tendon. A pitfall. J Ultrasound Med 1987;6:19-22.

11 Mathieson JR, Connell DG, Cooperberg PL, Lloyd-Smith DR. Sonography of the Achilles tendon and adjacent bursae. AJR 1988;151:127-31.

12 Lehtinen A, Taavitsainen M, Leirisalo-Repo M. Sonographic analysis of enthesopathy in the lower extremities of patients with spondylarthropathy. Clin Exp Rheumatol $1994 ; 12: 143-8$.

13 Olivieri I, Barozzi L, Padula A, De Matteis M, Pierro A, Cantini F, et al. Retrocalcaneal bursitis in spondylarthropathy: assessment by ultrasonography and spondylarthropathy: assessment by ultrasonography and magnetic resonance imaging. J Rheumatol 1998;25:

14 Brophy DP, Cunnane G, Fitzgerald O, Gibney RG. Technical report: ultrasound guidance for injection of soft tissue esions around the heel in chronic inflammatory arthritis. Clin Radiol 1995;50:120-2.

15 Cunnane G, Brophy DP, Gibney RG, FitzGerald O. Diagnosis and treatment of heel pain in chronic inflammatory arthritis using ultrasound. Semin Arthritis Rheum 1996;25:383-9. 